\title{
Challenging Physical Impossibility: Finding Your Way to Change Using Your Body and Spirit
}

\author{
Renae Cobley* \\ Mindset Coach, Australia \\ *Corresponding author: Renae Cobley, Mindset Coach, East Maitland, NSW 2323, Australia
}

Submission: 啙 December 04, 2018; Published: 眥 December 14, 2018

\begin{abstract}
Obesity prevalence is rapidly increasing worldwide requiring a collaborative, innovative, new energy, new ideas, and a new passion. Every person worldwide should be given equal opportunity to be healthy and well and learn the dimensions of their own physical power of resiliency. In building stamina, strength, dynamism, and enthusiasm for a new sense of self. The obesity epidemic is a fierce battle indeed requiring us all to dig deep and never has there been a more pivotal time to take our bodies for granted. Drastic times called for drastic measures, we must aim beyond what we are far capable of, develop a complete disregard for where our abilities end and do things we are incapable of. Noting along the journey that nothing is impossible. I provide a unique insight and details not seen or spoken about in such a mission. My secret weapon to this burden is operating as a "Mental Physical Coach Motivator" strategically manoeuvring people to have a higher awareness of bodily sensations, confidence, and new-found reality. It is not just about pushing the body to new limits. It is awareness of the spiritual resources hidden deep within. People testing both physical and psychological boundaries that remain largely untapped. The real epidemic is not just obesity, it is the need to educate on physical literacy, motivation, and adherence to exercise.
\end{abstract}

Along with the personal reinvention of people and to challenge people's thoughts. So, few people ever champion themselves and win with the best version of themselves. If we are physically fit than we become more inspired. Physical activity is a critical component of weight management and maintaining weight loss by any treatment in the fight against obesity.

\section{Mini Review}

Physical inactivity and low fitness levels are highly prominent in today's world. The challenge lies in the fact that:

1. no magical pill can be created to mimic the effects of challenging our cardiovascular fitness;

2. no weight loss surgery can release you from the need to exercise;

3. no nutritional program ever designed has combated the need to not move our bodies and;

4. no intense psychological session through utilising motivational interviewing and cognitive behavioural therapy has halted the merits of our bodies strong desire to seek physical fitness.

One in 10 deaths worldwide are attributable to physical inactivity, according to Dr Nick [1]- 70\% of us are not meeting recommended exercise for our health. What we do know, exercise is the most potent medicine in the world. So why is such low hanging fruit not maximised in medicine more? Physical activity is an incredibly underutilised therapy. Exercise is an essential determinant of health, and has beneficial effects on aerobic fitness, insulin sensitivity, blood pressure, and coronary heart disease risk reduction, regardless of a patient's weight. Exercise protects our brains, our emotions, memory, and resilience to stress. Every one of us has a significant contribution to make in promoting physical activity worldwide.

Exercise improves brain health, and in return we get more neurons. Neurogenesis happens, when you exercise you get more connections for learning and memory. As health professionals, we need to feel competent in empowering, transforming and inspiring patients. To routinely prescribe exercise programs for not just weight loss but for healthy living. Sedentary lifestyles play a significant role in contributing to obesity. The increasing prevalence of obesity is reflective in that most of the population has fallen short below such a level of physical activity. Asking patients about the type and amount of physical activity they undertake on a daily basis, provides clues about the amount of energy they expend daily in their lives.

Many overweight people switching off from their bodies movement patterns and focusing unconsciously on a diet alone. This is known to be true, reflecting purely on statistics of referred patients to dietitian's verse exercise physiologists. An enormous shift is required to focus more on the achievement of greater lifestyle inventions. Shifting away from conversations of not only nutrition and diet. To feel confident and inspired to review other forms of therapy. Such as lifestyle modifications that contribute significantly 
towards good health and weight management: Activity, exercise, coping mechanisms, stress management, a sense of purpose and the key drivers of our patients.

I work collaboratively and proactively with patients to train the brain, change the mindset and create an entirely new lifestyle. The fitness problem is more about mental failures than people's physical shortcomings. The best goal an obese person can set themselves is to "live the healthiest life they can." Living a life, they actively enjoy and embrace.

The ISSUE-The inconvenience of healthy living involves effort. The issue with EFFORT, its embracing behavioural change. Behavioural change is difficult for everyone. Informing, educating and showing people statistical results is not the problem. There is nobody in this world that wants to be obese. The majority of people are desperate to change their lives. If you have a look at the number one "New Year's Resolutions" is to get fit and healthy. The entire health and fitness markets make substantial gross profits currently at this time of year, to minimal patient benefit and measureable outcomes. The aftermath of people's vulnerability and guilt - the solution appeared so simplistic. Buy this product, do this, do that and you will drop the pounds. Along with eat less and move more are we really oversimplifying it?

Any chronic disease is $80 \%$ preventable by lifestyle changes. The SECRET-you cannot bring 50\% effort and expect $100 \%$ results. Nor is the equation $80 \%$ nutrition and $20 \%$ exercise, again oversimplification. It is $100 \%$ mindset. Training our patients to know good things take time and application of being consistent. What we do the majority of the time far outweighs what we do occasionally.

The reality of the weight loss journey is it takes time, it takes perseverance, it takes never giving up and fighting through the hard days. The brain is hardwired to move towards pleasure and avoid any pain. It's darn hard at times. Slowly we progress to a nonsustainable approach. If people feel like what they are doing is suffering, people will always ultimately quit, its how humans brains are hardwired.

Dieting and exercise are not enough alone. People must drop the emotional burden attached to a heavy load they carry. As health professionals, we need to eliminate suffering. Most people where they are at, could not happily live there life like it is for the rest of their time. Hence why weight loss relapse is so high. The mismanagement of stress is an innate mechanism in our body that makes us travels backward and does not propel us towards our goals. Firstly embrace imperfections and then fix broken attitudes.

It's about taking off the armor, changing how people show up, motivating people, start pressing on the hard conversations. An attitude a mindset, challenging physical impossibility-Its something you build and practice just like building muscle. As health professionals we push people away, we refer out often-it's more comfortable than having to work through the tough stuff.

In overcoming any limitations or any physical impossibility people have to surrender-They must finally let go and trust the process. It's about taking a massive leap of faith. It's going against all the chemicals in the brain and thrusting yourse. If into the other corner of the room and implicitly trusting. Unfortunately, most clinicians see patients over surrender, well that's just lazy.

I can tell what people expect by what they do. It reflects in their behaviour. As humans we become most powerful when we give up control, you step into the flow. To be ok with self. These people don't think about winning, losing weight and becoming more active. What they are coached is that we all can be more self-aware. Focused on the ability to observe self. To know:

1. Good things are supposed to happen to them, to believe that and expect that

2. Knowing they are simple enough

3. We all have something special, talents and abilities.

The key is unlocking that special something - the desire to change, that spirit, that fire inside that burns bright. Nothing has ever been fixed by what has not been acknowledged. The parallels between physical activity and mindset are enormous. The mental, emotional and spiritual is what fulfill us. SPIRIT is this magical life force, you become connected to, you can develop a relationship with.

To change you have to be greater than your environment. In our minds, we continuously fabricate a barrage of excuses that prevent us from acting. Then we form a belief that it's all going to be too hard. So, what do I suggest, the more you do, the more you learn. If you want to succeed you have to make what is familiar, unfamiliar. Our minds love what is familiar and is programmed this way to keep us going, over and over again. Providing momentum to keep us going. To continue living unconsciously, hence the dilemma we face in today's society. Not to mention the power of our vocabulary we feed ourselves daily. Not the food, but instead the dialogue we feed ourselves. Most overweight and obese peoples vocabulary are entirely undigestible. These people consuming overwhelmingly vast quantities of undigestible thoughts and belief patterns.

Everything we feel as humans are down to two things, the pictures you have in your head and the words we use. Your mind listening all the time. I hear far too often in consults, i should go on a diet, i should go to the gym or i should start exercising. It's too hard, I can not cope - their mind is telling them they shouldn't do something, so they procrastinate and lose flow. "Should and can not or its to hard" is the complete opposite of choice, presupposing that you should do these things, but really you don't. Feeling you have options come freedom, ability to make decisions that serve you and are not holding you back. Your minds number one job is to listen intuitively to what it is you want. Our brains are so intuned with us.

As humans, we are consistently subjected to our own thinking, its all mostly negative, limiting and unuseful information. The primary objective of this self-talk is to keep us safe, within our boundaries and contain us within the parameters of our comfort zones. All of us need to educate people and allow them to understand that this selftalk is not real. Our brain is a mere factory, so much is automatically 
operating in the background. By the time most of us reach 35-40 years of age we stop inputting new programming and work of old stored data.

Only when you listen and firmly believe in your self-talk does it become real $97 \%$ of what we are is memorised in the subconscious as patterns. Mentally rehearsing in the brain will appear as vivid as if the activity has taken place, creating a map to the future.

I get clients to visualise activity before they even start to lace up their joggers. To commence wiring and firing new circuits, before any scheduled activity. Getting people to believe they can change the brain by just thinking alone. The act of rehearsing who they are going to be. I get the body and its movement patterns to start to transform by thought alone first. Getting people to live by different emotions before progress really takes place.

To journey with people, we need to understand where they have come from and that takes time. It's about setting people up for the win and detonating negativity. Words have power. Interrupting the narrative that our patients tell themselves in their head and to learn to rally with it and take it on. Who of us has got to know our brain and thought patterns, learned to defend self from negative thinking and toxic self-talk? No amount of exercise will save us. I genuinely believe inside us all lay the most dormant powers of strength, protection, control, and awareness. The brain when active we know fires greater neurotransmitters and boosts brain power. To have the body and physical fitness one desires is not solely reserved for a few of us. It is achievable to everyone. What is required is, however, a supreme mental toughness, the ability to push through, to set goals, to strive relentlessly towards your goals. Long-term stamina, determination. To do whatever is necessary to fuel your mission and a new mindset to conquer new results.

Anything that is different pushes us to act impulsively. Everything we want and need; the brain perceives as a threat. We know what happens, increased cortisol, decreased the ability for actions and the body regards us as being under a state of danger. Resulting in unmet expectations, stress, reduced dopamine, poor performance, and decreased confidence. Under the duress of pressure, we immediately resort and push to our long-term memories. Bringing up times when weight loss failed us and did not work. Therefore, the sheer emergence of wanting to make a change, as confident as we are. Everything already is immediately against us, surfacing the potential to bring up bad memories. Our brains are so full of deceptive messages. Just because we think it, does not make it right, don't accept it, just acknowledge and let it go. To know it's coming from a recalled memory, just let the memory pass on by.

We need to become articulate enough to learn to engage with the intelligence of our own conscious awareness. Refuse to give in to the negative self-talk. Informing self, your body I am here to share with you that you can go well beyond what the mind is saying. Our central governor in our brains can be pushed. I acknowledge this often working with elite athletes and highly successful individuals. It has been tested and researched on numerous occasions. Mindset is so very critical for undergoing any element within the self of transformation. Finding the purpose that drives you, drives everything about you, moves you to bigger and better. Beyond anything, you have known. Knowing that you are enough.

All paths to weight loss can be complicated and traumatic, at the commencement of your journey. The prospect of asking anyone to move more than $100 \mathrm{~m}$ with over 100 pounds plus strapped to you. Legs chaffing together, feeling a heavy chest, aching legs, sore knee joints, feeling intense and utter fatigue, embarrassment, selfhatred, and low self-worth. Consistently we must educate people how can they expect to be paid when you have not done the work. Quitting is not an option when you have only just started. How are we getting bigger when we are amid a fitness boom, another running boom, and a nutritional boom. These industries worth billions of dollars. In fact, the world should be a much leaner and appropriate version than what we currently are.

It is well known by scientists, we must repeat to remember. Memories are volatile, so we must repeat to remember. The more elaborate we encode information at the moment of learning, the stronger that memory forms. It can take years to consolidate memory, not a few consulting minutes or sessions. The human brain has not been designed for long-term stress. Stress damages every kind of cognition that exists. Emotional stability is so important and a great predictor for success in weight loss. Your body is merely a screen onto which is projected the nature of your thoughts. Changing your mind, you alter every living cell in your body. Our lives are built in our subconscious mind. Fear within us has built a wall, each brick being; pressure, stress, greed, guilt, embarrassment, shame and burden. When the weight is gone from consciousness, it will be gone from the physical experience. I get people getting to know the part of them that overeats. To judge any aspect of self as ugly is abuse to one's self. This conflict of the habitual patterns within patients continues self-hate and sabotage. The weight people carry is nothing in comparison to the burden on their hearts. The sadness, anger, and shame in the stories they share personally in consults.

I insist on people asking self why you hate your body for being overweight? Your body didn't do this to you, you did this to it. You have not been abused by your body, your body has been abused by you. Is it your body your hate, its size, its shape? All negative emotions are derived from fear. If you hate your body, you fear something, and the question is what it is? Your body has not done anything to you, it has merely reflected the raging battlefield going on in your mind.

The battle refers to the inner struggle of having a desire to continue to push onwards through pain and fatigue, while a voice urging you to stop, our mind pushes us towards these urges, to give up or do not care. But feeling more and teaching your brain how to accept and understand the call. Your head and your attitude, your mind will fight you a fierce battle. You must win the spiritual battle. We are too often looking for more signs to end the fight than to win it. How do you win the psychological struggle? It must become a habit and work every day.

I understand by listening diligently to peoples stories, that food never feels like it lets them down, for many it is the only one stable 
thing in their life. While everything else feels like it is letting them done, whereas food doesn't. How rare is it to have a permanent thing in your life you can always derive pleasure from. I request people to please feed their hunger and restore their soul. Relationship with food is a relationship with self and everything in your life. There is no reason to think you're capable of loyalty until you address your fundamental disloyalty with the person living inside of you. What makes emotions different is not what you feel it's how you process them and sometimes how you cannot process them. The only way to remove the weight of processed feelings is to allow yourself to feel them. Emotions need to be handled in the same way as food.

1. We don't eat food that has been sitting out for a few days

2. We wash our food

3. We should have respect and love for food we eat

4. We require our food to be chewed for it to be digested

Emotions need to be handled, cleansed and absorbed in your psyche the same way as food involves balance. The compulsory eater gorges on food to suppress feelings. As humans, we suppress what we are too afraid to feel, will little or no trust in their emotions. Absolutely everything despite the pain is here to tell us something. The subconscious these days, cannot decide between a dangerous threat and tolerable stress. Does not know what to let in and what to let out. It stands to guard against everything. Emotions cannot be left untreated, feelings are potent forms of energy. People have two choices; to feel the emotion or listen to the outrageous demand to do something temporarily not deal with the pain. I train and educate people to feel fear and feel pain and be not afraid, learn the lesson and emerge out the other side. People must acknowledge that anxiety, depression, loneliness, anger, rejection, and grief are all great signs you are human. This suffering does not make you weak, only the avoidance makes you vulnerable.

Does society today contribute, the environment we find ourselves living in. The answer, in short, is yes it does. Our community is obsessed with cheap happiness. There is no reason in today's abundant, digital and wealthy world we live in to reach or run towards food. So why are we? Many of us are seeking to avoid the simplistic daily stressors of living in a highly fast, paced today's society. As humans, we are so utterly desperate to anesthetise self, and we will find anyway. Addicted to sugar, processed foods and the cycles of repetitive eating, because we feel so overwhelmed.

We need to change the mindset, the mentality around it and find the spirit within self. The human brain is so overrated and full of flaws. Does not always make the right choices, and our behavior produces results. You don't like your results, change your habits and rituals. Most results come from behaviour modification. We need to understand why we do what we do to change behaviours. We are entirely unconscious of most conversations and dialogue running on autopilot in our heads. Nothing means anything until we assign a meaning to it.

Emotions should only be concerned with the present, NLP models that everything goes through a filter process. Our emotional response is based on our programming. We Need to change the programming. If we can improve our perceptions about the exercise, we may feel different. The emotional cost of being overweight is incalculable. The battle only gets more comfortable as our patients get stronger - both mentally and physically, develop control, focus and as they form rituals. Focusing on the process that makes the habits and results will always follow.

I used myself as the experiment, the researcher, continually living like a rat in the laboratory. Wanting to evolve and grow. Everyone needs to give themselves permission to self-experiment. To run the race in life. Seldom do people self-experiment. It is partly the reason I work with elites and highly successful people. As these people are more highly programmed to self-experiment. Those that firmly believe they are enough. Those that do what they absolutely hate to get to where they want to go. Those that just take NO as an answer. Those that take action every day in their lives to feed them in the direction of their dreams. As the transformations and levels they seek, need and want is genuinely remarkable. You may ask where does the most significant victory lie? That I believe of selfdiscovery. Know thyself. There can be no more substantial victory than to know thyself. Most humans think that inner life is not as important as long as they exist on this earth, living the outer life.

Everything in our life mirrors back to what we reflect on being right. I give people the ability to own their own story. I get them ready for the adventure. I explain like boarding a flight. I ask where out of everywhere in the world would they like to fly. Then we start packing and organising to get ready for the journey.

People must have self-worth, love and to feel and know they matter. It is intensely challenging to get people within the fitness arena to acknowledge that apart from the physical tools we utilise so often. One of the most useful tools I use is empathy. The use and credibility of developing the mastery of soft skills. To transport people towards there goals. The body is a machine. Most overweight people have not moved their frame in years. I get people to acknowledge the positive energies around and within them. Them recognising strengths and have gratitude within. I allow people to realise that rewiring their brain is a process.

We live in the $21^{\text {st }}$ century a generation where we find comfort and celebration in food everywhere, we are conveyed such mixed and incorrect messages-we are in a daze, confused. It's about acknowledging the spiritual journey. People of all cultures and religions seek higher levels of spirituality in fasting. To gain mental clarity and to increase their mental cognition. There is a spiritual component, being more in tune with your body, without the presence of food. Our beliefs matter. Beliefs for too long have been ridden off in hard science and the academic arena. Our subconscious dramatically impacts our lives. Take advantage of your subconscious to influence your everyday lives. We must act and behave by who we want to be, instead of on the flip side of trying to will our minds into changing our behaviours.

Learn to question your patients, asking what pain do they want in their life? All people want a fantastic physique. But you don't 
end up with one unless you legitimately appreciate the pain and physical stress that comes with living inside a gym for hour upon hour unless you love calculating and calibrating the food you eat, planning your life out in tiny plate-sized portions [2]. A lot of fitness leaders are not trained in motivation, adherence and how to keep people connected. The health care and fitness industries require greater alignment. They attempt to make it fun. If you're doing it always for fun, you're not doing it right. Physical fitness involves intensity, duration, frequency, flexibility, balance, cardiovascular and resistance.

I educate patients that It's more manageable to work out daily and in the morning. As the brain must work less. You don't have to wrangle with what days you're going to work out and cannot flip days over. You cannot negotiate whether you need to work out. Working out in the mornings, we know immediately it is a $300 \%$ greater chance than getting it done as you increase your probability.

Today's climate has so radically changed, and our biology has remained the same. Energy expenditure required for daily living has been continuously declining, and we are living in an era of abundance of food.

Nothing is going to change regarding a shift, for it to happen it would have to be so incredibly radical. Neither is our biology. Humanity can overcome immense problems, we must conquer this deemed impossibility. How can we accommodate unchanged biology? But such a rapidly changed environment. Our biology attracts us to food and our preference becoming to not move is slowing killing us, we all need to share our knowledge, continue to collaborate, research and have a passion for winning this battle.

Never before have we lived in such an era where the quality of our lives is increasingly threatened by chronic disease. The ability to incorporate physical activity into our everyday lives is essential for disease prevention such as obesity. Are we failing in our attempts as not a single country has managed to significantly reverse or reduce the obesity rates? Can exercise hold the potential to be part of the solution for the ongoing obesity epidemic? Decreased energy expenditure alone does not hold as the root of the problem of obesity. However, it does play a significant role and part as providing one solution for obesity. Adopting a physically active lifestyle hold many beneficial outcomes apart from dropping and maintaining weight. My approach is in making a societal change to enhance human wellbeing rather than to prevent a particular symptom, such as obesity.

I think we have lost ourselves, and in return lost the ability to feel good about ourselves. Seldom are people able to uncover a sense of spirituality within the self. Spirituality is known to promote satisfaction in life and happiness. Patients complain today in a complex mix of mental, physical and other problems which impact on people's abilities to feel stress. Stress is a significant contributor to lives becoming fragmented and imbalanced. A correlation exists in people who are less satisfied in their lives than those who are happy and calm. For people to grow in their life, they need growing in awareness and meaning in their life. Obese people often feel humiliated in seeking such advice. It is not the physical consequences that matter the most to the obese, "To lose confidence in one's body is to lose confidence in one's self" [3].

The Dalai Lama, when asked what surprised him most about humanity, he said:

"Man. Because he sacrifices his health to make money. Then he sacrifices money to recuperate his health. And then he is so anxious about the future that he does not enjoy the present; the result being that he does not live in the present or the future; he lives as if he is never going to die, and then dies having never really lived." [4].

People need to gently place a microscope over their life. To allow for the first time, to see everything magnified perfectly clearly. As for the many, success lies in the architecture of the brain and the power of conducting daily baseline movement and fitness. Together we must all continue to challenge the physical impossibility in our patients.

\section{References}

1. Nick F (2018) How much exercise you need to be healthy.

2. Manson M (2018) The most important question of your life.

3. Simone De Beauvoir (2018) To lose confidence in ones.

4. Dozois D (2018) Not the years in your life, but the life in your years: Lessons from canadian psychology on living fully. Canadian Psychology 59(2): 107.
Creative Commons Attribution 4.0 International License

For possible submissions Click Here

\section{Submit Article}

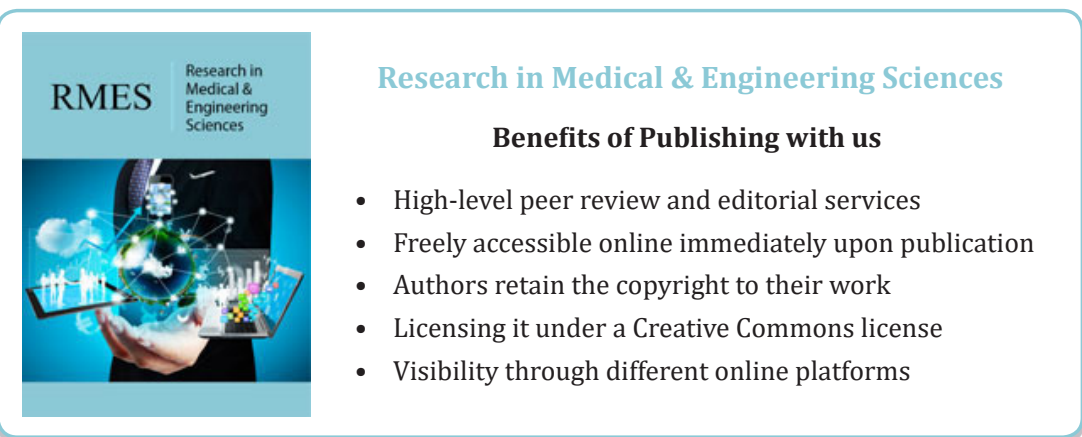

